\title{
Neuropeptides and Neurotransmitters Involved in Generalized Epilepsy: How Can the Antiepileptic Effect be Improved?
}

\author{
Felix-Martin Werner ${ }^{1,2^{*}}$ and Rafael Coveñas ${ }^{2}$ \\ ${ }^{1}$ Higher Vocational School of Elderly Care and Occupational Therapy, Thuringia, Germany \\ ${ }^{2}$ Laboratory of Neuroanatomy of the Peptidergic Systems, University of Salamanca, Salamanca, Spain
}

*Corresponding author: Felix-Martin Werner, neural networks in neurological and psychiatric diseases, University of Salamanca, Instituto de Neurociencias de Castilla y León (INCYL), Spain, Tel: +34/923/29 44 00; Fax: +34/923/29 45 49; E-mail: felixm-werner@versanet.de

Received date: June 19, 2015; Accepted date: July 17, 2015; Published date: July 22, 2015

Copyright: $\odot 2015$ Werner FM et al. This is an open-access article distributed under the terms of the Creative Commons Attribution License, which permits unrestricted use, distribution, and reproduction in any medium, provided the original author and source are credited.

\begin{abstract}
Here, we describe the alterations of neurotransmitters and neuropeptides that act on specific subreceptors in the brain areas involved in generalized epilepsy. A neurotransmitter imbalance between GABAergic and serotonergic neurons with hypoactivity and glutaminergic and dopaminergic neurons with hyperactivity is described. Considering the alterations in neurotransmitters and neuropeptides, neural networks in the hippocampus, hypothalamus, thalamus and cortex are described. The mechanisms of action of some recently developed antiepileptic drugs are addressed. In sum, a multimodal antiepileptic pharmacotherapy acting at several specific subreceptors is suggested. We recommend the development of an antiepileptic drug, that exerts simultaneously a GABAA agonistic and an NMDA antagonistic effect.
\end{abstract}

Keywords: Generalized epilepsy; Antiepileptic drugs; Dopamine; Serotonin; GABA; Glutamate; Acetylcholine; Levetiracetam; Lamotrigine; Topiramate

\section{Introduction}

Generalized epilepsy (grand mal and petit mal epilepsy) has a prevalence of $0.7 \%$ in the population. Generalized epilepsy can be idiopathic, while the susceptibility genes have been identified or symptomatic, the primary cause of which may be a tumour, a stroke or an episode of meningitis [1]. Often, status epilepticus, i.e. a sequence of seizures without patient recovering consciousness, cannot be treated with gamma-aminobutyric acid (GABA)A agonists [2]. In the epileptic foci, alterations of ion channels, e.g., altered sodium, chloride, calcium and potassium currents, and alterations of neurotransmitters and neuropeptides have been described [3]. In this sense, a neurotransmitter imbalance with GABA hypoactivity, via GABAA receptors, and glutamate hyperactivity, via ionotropic glutamate receptors, increases ictogenesis [4]. Furthermore, other neurotransmitters (dopamine and noradrenaline hyperactivity and serotonin hypoactivity) and neuropeptides (galanin and neuropeptide $\mathrm{Y}$ hypoactivity) play an important role in ictogenesis [4]. A neurotransmitter imbalance between anticonvulsant GABAergic and excitotoxic, proconvulsant glutaminergic neurons is located in the hippocampus and depends on the thalamocortical and neural circuits and on the interactions between the hippocampus and hypothalamus [4]. In light of the foregoing, here we describe the neural networks in the hippocampus, hypothalamus and thalamus involved in generalized epilepsy and the antiepileptic effects of current and recently developed antiepileptic drugs [5].

\section{Generalized epilepsy: alteration of classical neurotransmitters and neuropeptides}

In epileptic foci, both GABA hypoactivity, which reduces the activity of dopaminergic neurons through a presynaptic effect via GABAA receptors, and glutamate hyperactivity, which mostly has an excitotoxic, postsynaptic excitatory effect on ionotropic receptors and a partly presynaptic inhibitory effect, have been reported [6]. Catecholamines, i.e. dopamine and noradrenaline, show hyperactivity and serotonin shows hypoactivity. Noradrenaline only has an anticonvulsant effect at high doses, whereas at low doses it exerts a proconvulsant effect [4]. In ictogenesis, neuropeptides act as neuromodulators. The effects of classical neurotransmitters and neuropeptides in ictogenesis will be described below.

\section{Gamma-aminobutyric acid}

Gamma-aminobutyric acid (GABA) is a presynaptic inhibitory neurotransmitter which exerts its effect upon GABAA and GABAB receptors. In animal studies, GABA withdrawal or GABAA antagonists can prolong epileptic seizures, whereas GABAA agonists and NMDA antagonists show antiepileptic properties [7]. Status epilepticus, which cannot be treated with GABAA agonists, can often be treated with N-methyl-D-aspartate (NMDA) antagonists [8]. GABAB receptors are also involved in ictogenesis [9]. Thus, there are two issues to be addressed: 1) whether GABAB receptors exert a protective function upon GABAA GABAergic neurons, and 2) whether $\mathrm{GABAB}$ antagonists exert an antiepileptic effect [9].

\section{Glutamate}

Glutamate mainly exerts an excitotoxic effect on ionotropic receptors, i.e. NMDA, kainate (KA) and alpha-amino-3-hydroxy-5methyl-4-isoxazolepropionic acid (AMPA) receptors, together with a partly presynaptic effect [10]. In the hippocampus, through ionotropic receptors glutaminergic neurons can activate D2 dopaminergic 
neurons, and they can inhibit presynaptically 5-hydroxytryptamine (HT)2C serotonergic neurons. Metabotropic glutaminergic receptors are also involved in ictogenesis, since the activation of subtype 5 of metabotropic glutaminergic receptors (m5Glu receptors) has a proconvulsant effect [11].

\section{Dopamine}

In seizures, dopamine has a modulating effect [12]. The proconvulsant or anticonvulsant effect is mediated via D2 receptors. GABAergic neurons showing hypoactivity and located in the hippocampus, weakly inhibit presynaptically D2 dopaminergic neurons. GABA hypoactivity and dopamine hyperactivity can enhance an epileptic seizure [4].

\section{Noradrenaline}

In generalized epilepsy and major depression, alterations of noradrenaline and serotonin, both of which exert a postsynaptic excitatory effect, and of GABA and glutamate, which exert a presynaptic inhibitory effect, have been described [13]. At low doses, noradrenaline can enhance an epileptic seizure, whereas at high doses it has a protective effect on seizures [14].

\section{Serotonin}

Serotonin, a mainly postsynaptic excitatory neurotransmitter, has pro- and anti-convulsant effects in ictogenesis. In patients with a comorbidity of generalized epilepsy and major depression who were treated with a selective serotonin reuptake inhibitor, the treatment for the generalized epilepsy was maintained. The antiepileptic effect was achieved via activation of 5-HT1A receptors [15]. Clinical trials should be carried out in order to determine whether $5-\mathrm{HT} 2 \mathrm{C}$ or $5-\mathrm{HT} 7$ agonists might exert an antiepileptic effect, as observed in animal experiments [16]. In the hippocampus, glutaminergic neurons via NMDA receptors might strongly inhibit presynaptically 5-HT2C serotonergic neurons [4].

\section{Acetylcholine}

Acetylcholine, which exerts its effect on muscarinic and nicotinic cholinergic receptors, has a pro- and an anti-convulsant action. The activation of the muscarinic-1 (M1) receptor has a proconvulsant effect [17]. Alpha4beta2 nicotinic cholinergic (alpha4beta2 nAch) neurons activate D2 dopaminergic neurons and alpha7 nAch neurons activate GABAergic neurons located in the hippocampus [18].

\section{Dynorphin}

Dynorphin plays a role in ictogenesis, and kappa opioid receptor agonists may exert an antiepileptic effect [19].

\section{Galanin}

Galanin exerts its effect upon Gal1, Gal2 and Gal3 receptors and its activation or blockade is important in neurological diseases and generalized epilepsy. Gal1 receptor agonists may have antiepileptic properties, because they activate 5-HT2C serotonergic neurons $[18,19]$.

\section{Neuropeptide Y}

Neurons containing neuropeptide Y (NPY) and located in the dentate gyrus inhibit GABAergic neurons, via NPY1 receptors, and inhibit glutaminergic neurons via NPY2 receptors. In animal studies, NPY2 receptor agonists, which inhibit the epileptogenic glutamate release, have been found to exert the highest antiepileptic effect [20].

\section{Generalized epilepsy: neural circuits}

Neural networks in the hippocampus, hypothalamus and thalamus, shown in figure 1, can be described as follows: D2 dopaminergic neurons with a high activity strongly activate glutaminergic neurons, which strongly inhibit 5-HT2C serotonergic neurons via NMDA receptors. Glutaminergic neurons also exert an excitotoxic effect on D2 dopaminergic neurons via NMDA, AMPA and KA receptors and can enhance ictogenesis. 5-HT2C serotonergic neurons weakly activate GABAergic neurons, which weakly inhibit via GABAA receptors D2 dopaminergic neurons. Withdrawal of the GABAergic presynaptic inhibition of D2 dopaminergic neurons can set off an epileptic seizure. GABAergic neurons weakly inhibit glutaminergic neurons located in the thalamus, which activate other glutaminergic neurons located in the cortex. Cortical glutaminergic neurons, via NMDA receptors, can activate D2 dopaminergic neurons located in the hippocampus. 5HT2C serotonergic neurons weakly activate GABAergic neurons, which weakly inhibit A2A adenosine neurons via GABAA receptors. A2A adenosine neurons with a high activity strongly activate glutaminergic neurons, which strongly inhibit 5-HT2C serotonergic neurons via m5Glu receptors. Hypothalamic galanin neurons weakly activate 5-HT2C serotonergic neurons via Gall receptors, and 5-HT7 serotonergic neurons exert a weak postsynaptic excitatory effect upon 5-HT2C serotonergic neurons. In the dentate gyrus, neuropeptide $Y$ neurons inhibit GABAergic neurons via NPY1 receptors and inhibit glutaminergic neurons via NPY2 receptors. Nicotinic cholinergic neurons activate D2 dopaminergic neurons via alpha4beta2 nAch receptors and activate GABAergic neurons via alpha7 nAch neurons [18]. 
Page 3 of 4

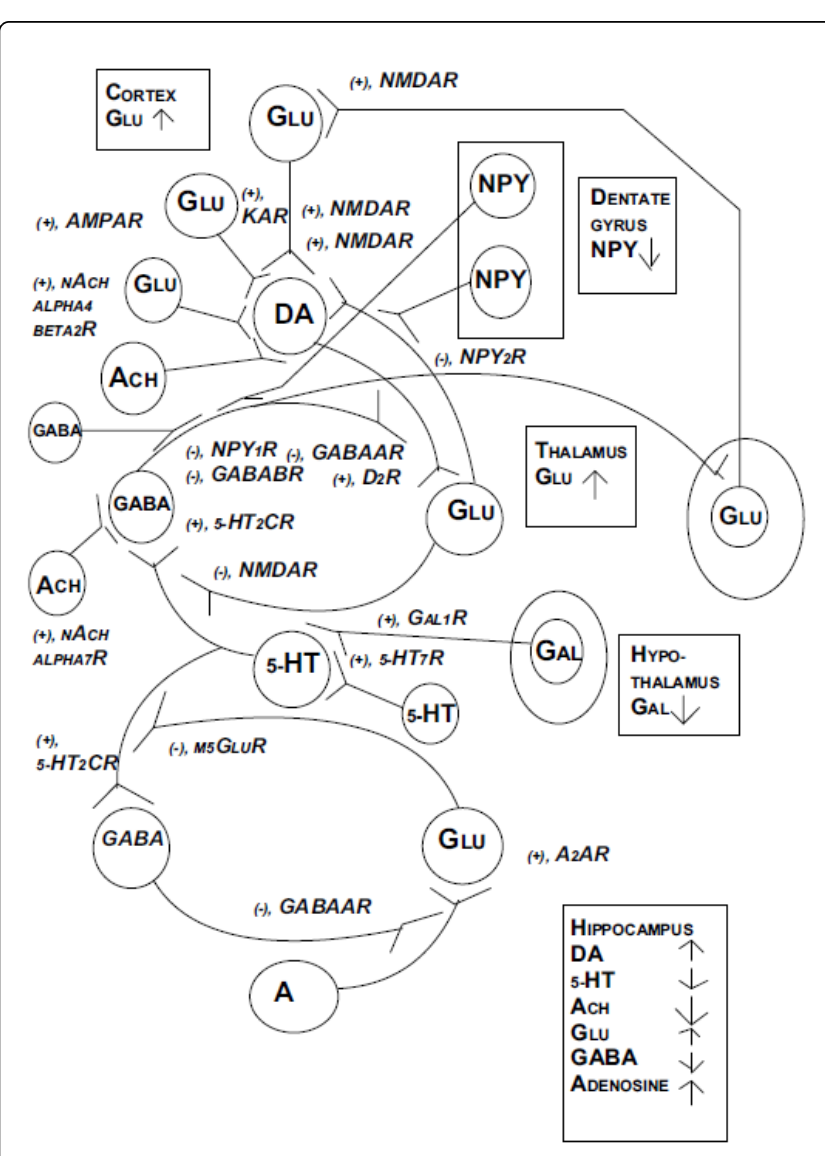

Figure 1: Neuronal pathways, classical neurotransmitters and neuropeptides involved in generalized epilepsy. 5-HT: serotonin; A: adenosine; Ach: acetylcholine; DA: dopamine; GABA: gammaaminobutyric acid; Gal: galanin; Glu: glutamate; NPY: neuropeptide Y. The following subreceptors are indicated: A2AR: A2A receptor, a subreceptor of the adenosine receptor; AMPAR: AMPA receptor, a subreceptor of the ionotropic glutaminergic receptor; GABAAR: GABAA receptor, a subreceptor of the GABA receptor; GABABR: GABAB receptor, a subreceptor of the GABA receptor; 5-HT2CR: 5-HT2C receptor, a subreceptor of the serotoninergic receptor; 5-HT7R: 5-HT7 receptor, a subreceptor of the serotoninergic receptor; D2R: D2 receptor, a subreceptor of the dopaminergic receptor; Gal1R: Gall receptor, a subreceptor of the galanin receptor; KAR: kainate receptor, a subreceptor of the ionotropic glutaminergic receptor; m5GluR: m5Glu receptor, a subreceptor of the metabotropic glutaminergic receptor; nAch alpha4beta2R: a subreceptor of the nicotinergic ACh receptor; nAChalpha7R: nAch alpha7 receptor: a subreceptor of the nicotinergic ACh receptor; NMDAR: NMDA (N-methyl-Daspartate) receptor, a subreceptor of the ionotropic glutaminergic receptor; NPY1R: NPY1 receptor, a subreceptor of the neuropeptide Y receptor; NPY2R: NPY2 receptor, a subreceptor of the neuropeptide $\mathrm{Y}$ receptor. A plus mark indicates a postsynaptic excitatory impulse; a minus mark indicates a presynaptic inhibitory impulse. $\uparrow:$ increase; $\downarrow$ : decrease.

\section{Recently developed antiepileptic drugs in the treatment of generalized epilepsy}

Here, we describe the mechanisms of action of some recently developed antiepileptic drugs for the treatment of generalized epilepsy $[4,18]$. The activation or blockade of specific subreceptors of classical neurotransmitters and the blockade of ion channels are discussed.

\section{Lamotrigine}

Lamotrigine is approved for the treatment of childhood epilepsy. It blocks voltage-gated sodium channels, nAch alpha4beta2 receptors and NMDA receptor, and to a lesser extent AMPA receptors [21].

\section{Levetiracetam}

In children, levetiracetam is used for the treatment of refractory generalized epilepsy. It increases the presynaptic inhibitory effect of GABAergic neurons and blocks NMDA receptors [22].

\section{Rufinamide}

In children, rufinamide is an antiepileptic drug used as adjunctive pharmacotherapy for the treatment of Lennox-Gastaut syndrome. Rufinamide exerts an antiepileptic effect by prolonging the inactivity of sodium channels [23].

\section{Topiramate}

In children, topiramate is used for the treatment of generalized epilepsy. It blocks not only KA and AMPA receptors, but also NMDA receptors, and it stabilizes dopaminergic neurons [24].

\section{Zonisamide}

Zonisamide is accepted as an add-on therapy in generalized epilepsy and as an anti-Parkinsonian drug. It blocks $\mathrm{Na}+$ channels and $\mathrm{Ca}+$ channels and increases dopamine contents by inhibiting the $\mathrm{MAO}(\mathrm{B})$ enzyme [25].

\section{Possible treatments of generalized epilepsy according to the neural networks described}

According to the neural networks described, the following antiepileptic drugs or add-on therapies might be possible:

- Combined GABAA agonists and NMDA antagonists, since GABAA agonists and NMDA antagonists may stabilize the neural networks.

- NMDA, AMPA and KA receptor antagonists.

- NPY2 receptor agonists which inhibit glutamate emptying, and NPY1 receptor antagonists, which decrease the presynaptic inhibition mediated by NPY, would enhance the GABAergic presynaptic inhibition.

- Gall agonists, which would increase serotonin levels.

\section{Conclusions}

In the present work, in generalized epilepsy, we describe the alterations of neurotransmitters and neuropeptides in epileptic foci in the hippocampus. A neurotransmitter imbalance between presynaptic GABAergic neurons, with hypoactivity, and glutaminergic neurons, with excitotoxicity, enhance ictogenesis. Postsynaptic excitatory 
Citation: Werner FM, Coveñas R (2015) Neuropeptides and Neurotransmitters Involved in Generalized Epilepsy: How Can the Antiepileptic Effect be Improved?. J Neurol Neurophysiol 6: 303. doi:10.4172/2155-9562.1000303

Page 4 of 4

neurotransmitters are also involved in the neural networks, since dopamine hyperactivity via D2 receptors and serotonin hypoactivity via 5-HT2C receptors have a proconvulsant effect. Other neurotransmitters and neuropeptides and their specific subreceptors and their activation or blockade with alpha4beta2 nAch antagonists, alpha7 nAch agonists, 5-HT7 agonists, GABAB antagonists or KA or AMPA antagonists might have an additional antiepileptic effect. A multimodal pharmacotherapy acting at different subreceptors should be developed. Moreover, in this context we emphasize the importance of developing antiepileptic drugs exerting a GABAA agonistic and an NMDA antagonistic effect.

\section{References}

1. Mumenthaler M, Matte H (2008) Epilepsien und andere Erkrankungen mit anfallsartigen Erscheinungen und/oder Bewusstseinsstörungen. Thieme, Stuttgart.

2. Werner F-M, Coveñas R (2012) Behandlung des Status epilepticus anhand eines neuronalen Netzwerkes. www.anim2012.de.

3. Badawy RA, Harvey AS, Macdonell RA (2009) Cortical hyperexcitability and epileptogenesis: understanding the mechanisms of epilepsy - part 1. J Clin Neurosci 16: 355-365.

4. Werner FM, Coveñas R (2011) Classical neurotransmitters and neuropeptides involved in generalized epilepsy: a focus on antiepileptic drugs. Curr Med Chem 18: 4933-4948.

5. Barrera-Bailón B, Oliveira JA, López DE, Muñoz LJ, Garcia-Cairasco N, et al. (2013) Pharmacological and neuroethological studies of three antiepileptic drugs in the Genetic Audiogenic Seizure Hamster (GASH:Sal). Epilepsy Behav 28: 413-425.

6. Ketzef M, Kahn J, Weissberg I, Becker AJ, Friedman A, et al. (2011) Compensatory network alterations upon onset of epilepsy in synapsin triple knock-out mice. Neuroscience 189: 108-122.

7. Butuzova MV, Kitchigina VF (2008) Repeated blockade of GABAA receptors in the medial septal region induces epileptiform activity in the hippocampus. Neurosci Lett 434: 133-138.

8. Jacob TC, Moss SJ, Jurd R (2008) GABA(A) receptor trafficking and its role in the dynamic modulation of neuronal inhibition. Nat Rev Neurosci 9: 331-343.

9. Mares P, Tabashidze N (2008) Contradictory effects of GABA-B receptor agonists on cortical epileptic afterdischarges in immature rats. Brain Res Bull 75: 173-178.

10. Werner F-M, Coveñas R (2009) Klassische Neurotransmitter und Therapiemöglichkeiten bei generalisierten Epilepsien. www.anim2009.de.

11. [Tang FR, Chen PM, Tang YC, Tasi MC, Lee WL (2007) Two-methyl-6phenylethynyl- pyridine (MPEP), a metabotropic glutamate receptor 5 antagonist, with low dose of MK801 and diazepam: a novel approach for controlling status epilepticus. Neuropharamcology 53: 821-831.

12. Birioukova LM, Midzyanovskaya IS, Lensu S, Tuomisto L, van Luijtelaar G (2005) Distribution of D1-like and D2-like dopamine receptors in the brain of genetic epileptic WAG/Rij rats. Epilepsy Res 63: 89-96.

13. Kanner AM (2008) Mood disorder and epilepsy: a neurobiologic perspective of their relationship. Dialogues Clin Neurosci 10: 39-45.

14. Jurgens CW, Boese SJ, King JD, Pyle SJ, Porter JE, et al. (2005) Adrenergic receptor modulation of hippocampal CA3 network activity. Epilepsy Res 66: 117-128.

15. Thomé-Souza MS, Kuczynski E, Valente KD (2007) Sertraline and fluoxetine: safe treatments for children and adolescents with epilepsy and depression. Epilepsy Behav 10: 417-425.

16. PericiÄ $\ddagger$ D, Svob Strac D (2007) The role of 5-HT(7) receptors in the control of seizures. Brain Res 1141: 48-55.

17. Haug KH, Myhrer T, Fonnum F (2007) The combination of donepezil and procyclidine protects against soman-induced seizures in rats. Toxicol Appl Pharmacol 220: 156-163.

18. Werner F-M, Coveñas, R (2014) Mechanism of action of newer antiepileptic drugs: how to improve the antiepileptic effect? www.epilepsie2014.de.

19. Loacker S, Sayyah M, Wittmann W, Herzog H, Schwarzer C (2007) Endogenous dynorphin in epileptogenesis and epilepsy: anticonvulsant net effect via kappa opioid receptors. Brain 130: 1017-1028.

20. Meurs A, Clinckers R, Ebinger G, Michotte Y, Smolders I (2007) Clinical potential of neuropeptide $\mathrm{Y}$ receptor ligands in the treatment of epilepsy. Curr Top Med Chem 7: 1660-1674.

21. Glauser TA, Cnaan A, Shinnar S, Hirtz DG, Dlugos D, et al. (2010) Ethosuximide, valproic acid, and lamotrigine in childhood absence epilepsy. N Engl J Med 362: 790-799.

22. Boido D, Farisello P, Cesca F, Ferrea E, Valtorta F, et al. (2010) Corticohippocampal hyperexcitability in synapsin I/II/III knockout mice: agedependency and response to the antiepileptic drug levetiracetam. Neuroscience 171: 268-283.

23. Kluger G, Kurlemann G, Haberlandt E, Ernst JP, Runge U, et al. (2009) Effectiveness and tolerability of rufinamide in children and adults with refractory epilepsy: first European experience. Epilepsy Behav 14: 491-495.

24. Rawls SM, Thomas T, Adeola M, Patil T, Raymondi N, et al. (2009) Topiramate antagonizes NMDA- and AMPA-induced seizure-like activity in planarians. Pharmacol Biochem Behav 93: 363-367.

25. Sonsalla PK, Wong LY, Winnik B, Buckley B (2010) The antiepileptic drug zonisamide inhibits MAO-B and attenuates MPTP toxicity in mice: clinical relevance. Exp Neurol 221: 329-334. 